\title{
A Escuta Clínica Psicanalítica em uma Instituição Pública: Construindo Espaços
}

\author{
Elenice Cazanatto \\ Universidade Federal do Rio Grande do Sul, RS, Brasil. \\ Margareth Kuhn Martta \\ Universidade de Caxias do Sul, RS, Brasil. \\ Claudia Alquati Bisol \\ Universidade de Caxias do Sul, RS, Brasil.
}

\begin{abstract}
Resumo: Nos últimos anos, cada vez mais tem se ampliado a discussão sobre a presença da Psicanálise em locais diferentes do setting tradicional, tais como no serviço público e nas instituições. Com o objetivo de tecer algumas considerações sobre o trabalho em uma instituição pública que atende crianças e adolescentes em contraturno escolar, este artigo traz alguns recortes que representam possibilidades de intervenção, a partir da escuta clínica psicanalítica, em um diálogo entre a teoria e o contexto institucional. Por meio das observações e do trabalho realizado, acredita-se que uma instituição possível, na atualidade, seja aquela que permite aos que dela fazem parte espaço para serem reconhecidos de outras formas no social e advir/acontecer enquanto sujeitos. Para essas crianças e adolescentes que trazem em seu corpo e em seu psiquismo as marcas da exclusão e da violência, que, ao conviver em uma instituição, possam inscrever outras marcas e se reconhecer enquanto sujeitos, a partir de outros significantes.
\end{abstract}

Palavras-chave: Psicanálise, Instituições públicas, Crianças, Adolescentes.

\section{Listening to Psychoanalytic Clinic at a Public Institution: Building Spaces}

\begin{abstract}
In recent years, there has been an increasing discussion on the presence of Psychoanalysis in locations out of its traditional setting, such as public services and institutions. In order to make some considerations about working at a public institution serving children and adolescents in different school shifts, this study brings some considerations which might represent intervention possibilities from the Psychoanalytic Clinic Listening, in a dialogue between theory and institutional context. After observation, we were able to conclude that an institution can represent a space for people to be recognized in different social ways in order to help them to act as subjects/citizens. This analysis aimed to contribute with children and adolescents who bring marks of exclusion and violence in their body and psyche, to change their stories by being at an institution and to recognize themselves as subjects, from other signifiers. KeYwords: Psychoanalysis, Public Institutions, Children, Teenagers.
\end{abstract}




\title{
Escuchando Clínica Psicoanalítica en una institución pública: Construyendo espacios
}

\begin{abstract}
Resumen: En los últimos años, ha habido una creciente discusión sobre la presencia del psicoanálisis en lugares diferentes (tales como el servicio público y las instituciones) a los que tradicionalmente se encontraba. Con el objetivo de tejer algunas consideraciones sobre el trabajo en una institución pública que atiende niños y adolescentes en contra turno escolar, este artículo trae algunos recortes que presentan posibilidades de intervención, a partir de la escucha clínico psicoanalítica, en un diálogo entre la teoría y el contexto institucional. A partir de las observaciones y de los trabajos realizados, se cree posible que una institución, en la actualidad, sea un espacio que permita a los que de ella hacen parte ser reconocidos de diferentes formas sociales y llegar a actuar en cuanto sujetos/ciudadanos. Este análisis esperó contribuir a que niños y adolescentes que traen en su cuerpo y en su psiquis las marcas de la exclusión y de la violencia, al convivir en una institución, pudieran inscribir otras marcas y reconocerse en cuanto sujetos, a partir de otros significados.

Palabras clave: Psicoanálisis, Instituciones públicas, Niños, Adolescentes.
\end{abstract}

\section{Introdução}

Descobrir o que liberta o sol

Que faz buraco

Furação do escuro, escuro, escura [...]

(Trecho da música "Auto-Reverse", do grupo

"O Rappa")

$\mathrm{Na}$ atualidade, cada vez mais os profissionais que trabalham com o referencial psicanalítico ocupam espaços diferentes do setting tradicional, tais como no serviço público. No entanto, levar a prática clínica para outros contextos, sem subverter os fundamentos que sustentam a sua especificidade, ainda é considerado um tema que levanta questões e sugere ampliar os estudos. Autores contemporâneos (Figueiredo, 1997; 2005; Kupfer, 1997; 2005; Lebrun, 2009; Moretto, 2001; Soares, 2007; Rosa, 2004) discutem a importância, a pertinência e as especificidades do trabalho sustentado por aportes psicanalíticos em instituições públicas, que atende grande parte da população, em sua maioria, em situação de vulnerabilidade social e psíquica.

O presente trabalho nasce do desejo das autoras de sustentar uma prática institucional a partir dos aportes teóricos e técnicos da psicanálise. Com o objetivo de tecer algumas considerações sobre o trabalho em uma instituição pública que atende crianças e adolescentes em contraturno escolar, são trazidos alguns recortes que representam possibilidades de intervenção, a partir da escuta clínica psicanalítica, num diálogo entre a teoria e o contexto institucional.

\section{A escuta psicanalítica e o Lar da Infância: um desafio à prática}

O estudo sobre o social eas instituições está presente nos referenciais da psicanálise desde Sigmund Freud. $\mathrm{O}$ autor enlaça as questões do individual e do social, dizendo que toda a Psicologia individual é, ao mesmo tempo, social, na medida em que um indivíduo sempre está se relacionando com outros, seja como modelo, objeto, auxiliar ou oponente (Freud, 1921/1980). No texto "Linhas de Progresso na Terapia Psicanalítica", Freud (1918-1919/1976) escreveu que chegaria um tempo em que seria possível e necessário aplicar a psicanálise a grandes parcelas da população. Para tanto, ressalta a necessidade de adaptar a técnica às novas condições de trabalho, sem, contudo, modificar os pressupostos.

O avanço da presença da prática psicanalítica nas instituições acompanhou o próprio desenvolvimento da teoria psicanalítica. Nos trabalhos de Jacques Lacan, podemos encontrar o traçado de algumas linhas que ajudam a compreender as diferenças entre a psicanálise em intenção, referindo-se ao tratamento psicanalítico, propriamente dito, e à psicanálise em extensão, que se estende a outras produções humanas. Nessa perspectiva, se as instituições também estão sujeitas às leis de funcionamento da linguagem, torna-se possível operar lendo os discursos na instituição, da mesma 
maneira como se lê o discurso de um sujeito em tratamento (Lacan, 2001/2003).

De acordo com Rosa (2004), no trabalho realizado em instituições, é preciso fundamentar e debater os processos, as concepções e as políticas que as regem, visto que a prática psicanalítica é atravessada pelas dimensões éticas e metodológicas específicas. Trata-se de um outro olhar sobre a lógica de funcionamento institucional.

A instituição em questão neste trabalho, a partir da qual são tecidas algumas considerações, trata-se, atualmente, de um local destinado ao atendimento de crianças e adolescentes em contraturno escolar ${ }^{1}$. Fundado há mais de duas décadas, o local já passou por mudanças significativas em relação a objetivos e funções. Inicialmente, o Lar da Infância, nome fictício que é usado para denominar o local, estava destinado a abrigar jovens que viviam nas ruas de alguns bairros periféricos da cidade ou que chegavam de outras localidades sem ter onde ficar, funcionando como uma espécie de albergue. O local também já teve o objetivo de abrigar crianças e adolescentes afastados do convívio familiar por medida de proteção, conforme prevê o Estatuto da Criança e do Adolescente, realizando um trabalho educativo, assistencial e de preparação para o trabalho. Há mais de dez anos, vocacionou sua prática para o atendimento de crianças e adolescentes em contraturno escolar.

O início do trabalho de escuta psicanalítica na instituição aconteceu num momento de muitas dificuldades, tanto em relação à definição dos objetivos do serviço, quanto aos atendimentos realizados. Num primeiro momento, o principal objetivo foi escutar a demanda do local, pois partimos do princípio de que o trabalho em instituições deve levar em conta a demanda singular, sem desconsiderar a lógica institucional, o contexto social em que está inserida, o perfil de seus atendidos, ao propor um espaço de escuta dos sintomas ${ }^{2} \mathrm{e}$ das passagens ao ato ${ }^{3}$ que ali se apresentam.

No Lar da Infância, a queixa central dos profissionais e da direção é quanto à agressividade e falta de interesse dos alunos. Observou-se uma equipe bastante fragilizada, com cisões e distorções. Ao levantar as hipóteses sobre o funcionamento da instituição, foi possível observar que a insatisfação dos membros da equipe, as cisões e distorções e os conflitos entre os profissionais são, de alguma forma, abafados pela gritaria e por agressões de alunos, bem como as queixas da equipe em relação a estes. Questões importantes quanto ao lugar que a instituição ocupa no serviço público e na sociedade também foram surgindo.

Para Coutinho e Rocha (2007), o trabalho com a palavra, ou mais especificamente, com uma fala endereçada, permite que questões emergentes possam ser desdobradas e arejadas, abrindo possibilidades de intervenção e de investigação. Monteiro e Queiroz (2006) referem que, ao não recuar frente às dificuldades que encontra na instituição, o psicanalista depara-se com o desafio de localizar o seu lugar, não perdendo de vista o específico de sua posição, ou seja, a possibilidade de localizar e trazer para a cena o que dela está excluído, fazendo circular a causa do desejo.

$\mathrm{Na}$ instituição em questão observou-se que, ao propiciar um espaço para a manifestação e a escuta das questões institucionais, o que ficava à mostra era que não se tratava apenas de alunos agressivos e sem interesse, o que era explicado pelos profissionais como sendo resultado do meio em que residiam, mas também, de alunos agredidos por uma instituição onde outros interesses se sobrepunham ao cuidado e ao investimento voltado aos alunos atendidos. Às crianças e aos adolescentes ficavam as sobras, tanto da comunidade quanto do serviço público.

Uma observação que merece destaque é que a instituição lembrava um depósito, tanto de doações de alimentos, móveis, roupas e materiais, que chegavam a todo o momento, mas que na maioria das vezes não circulavam ou então não se faziam necessárias, quanto de profissionais, que não se adaptavam em outros serviços e passavam a fazer parte da equipe, sem o desejo de estarem ali, ou com objetivos alheios aos interesses institucionais.

Lacan (2001/2003) nos lembra que a função de resíduo exercida e mantida pela família conjugal (e talvez, pelas instituições onde a criança circula), é de outra ordem que não a da vida segundo a satisfação

1. A proposta de contraturno escolar foi regulamentada pela Lei de Diretrizes e Bases da Educação Nacional (Brasil, 1996).

2. Para Freud, o sintoma é uma formação de compromisso, o retorno daquilo que foi recalcado e que conseguiu chegar à consciência, pois atravessou a barreira do recalque, utilizando-se dos mecanismos de condensação e deslocamento (Laplanche, \& Pontalis, 2001). 3. Lacan delimitou a passagem ao ato como uma saída de cena, em que o sujeito se reduz a um objeto excluído ou rejeitado, como num salto no vazio/defenestração. Nesse caso, o ato não é "aquilo que quer dizer", mas corresponde "a uma ruptura do quadro da fantasia e a uma expulsão do sujeito" (Kaufmann, 1996, p. 55). 
das necessidades. Trata-se da constituição subjetiva, que implica a necessidade de um desejo que não seja anônimo na constituição do cuidado. Uma posição de sintoma no campo do desejo de um casal, de uma família ou de uma instituição. Oposto ao lugar de objeto do fantasma materno, e porque não, social e político.

Nessa perspectiva, torna-se importante trazer as considerações de Lebrun (2009), para quem o trabalho institucional na contemporaneidade consiste em afrontar o caos. $\mathrm{O}$ autor refere que, se nas décadas passadas o trabalho institucional era marcado pela necessidade de questionar as amarras institucionais, ou seja, aquilo que estava instituído, atualmente se trata de fazer o trabalho inverso: "Recordar que para a vida de um grupo, o instituinte deve desembocar no instituído. [...] É frequente refazer a instituição, o que se torna hoje o objetivo a perseguir!" (p. 23).

No Lar da Infância, pode-se levantar a hipótese de que a inserção da escuta clínica psicanalítica favoreceu que a palavra pudesse circular, tanto entre os membros da equipe quanto entre os educandos. Além disso, o entendimento clínico psicanalítico contribuiu para a criação de uma nova proposta de trabalho e a organização dos espaços e das rotinas institucionais. Esses movimentos possibilitaram que mudanças significativas fossem acontecendo.

Salas que serviam de depósito de materiais que nunca eram utilizados foram revitalizadas. A separação dos alunos em turmas, tendo como critério a idade, a demarcação de períodos para a realização das atividades e a organização de espaços destinados à realização do tema, aos jogos, ao vídeo ou para brincar, permitiu que aqueles que antes vagavam pelos corredores agredindo os colegas ou destruindo as instalações, participassem das atividades e dirigissem sua contestação aos profissionais. Por exemplo: numa das atividades o aluno solicitou à educadora para sair da sala. Quando lembrado de que a combinação é que só poderia sair da sala na troca dos períodos, ele contestou, xingou, brigou; no entanto, permaneceu no setor. Anteriormente não haveria sequer a solicitação, o aluno simplesmente sairia da sala e, muitas vezes, nem seria notado.

Para Soares (2007), um ponto em comum entre as definições de instituição é a referência à lei, aos pactos e às regras. De acordo com a autora, a lei é aquilo que barra o gozo excedente, ordenando o mundo entre o que é permitido e o que é proibido, o que possibilita o laço social. Ao proibir, a lei instaura a falta, exigindo uma posição criativa frente ao interdito e abrindo novas possibilidades ao sujeito, ao mesmo tempo em que instaura a dimensão simbólica.

De acordo com Lebrun (2009), a instituição sempre deverá estar na posição de um terceiro, sobrepujando seus membros. No entanto, o autor problematiza o lugar ocupado pelas instituições na atualidade, já que a mutação do laço social causa repercussões na a vida coletiva, em especial para as instituições. Se antes o lugar desse terceiro já estava legitimado pela tradição, na atualidade ele passa a ser questionado. Lebrun (2009) refere que, dessa forma, a intervenção em instituições também deve ser pensada de forma diferente. Para o autor, "a terceiridade, que sempre estava em circulação, doravante precisa ser, senão inventada, elaborada e inscrita, e então também precisa ser incessantemente construída, mas com o risco de não ter mais a estabilidade suficiente para constituir verdadeiramente um elemento terceiro" (p. 20).

$\mathrm{Na}$ instituição Lar da Infância, levanta-se a hipótese de que, ao organizar e delimitar os espaços físicos, oferecendo possibilidades para as crianças e adolescentes exercerem a criatividade, estudarem, brincarem, jogarem e interagirem com colegas e profissionais, também foi possível a construção de espaços psíquicos para os sujeitos. Assim, mesmo com muitas resistências, aos poucos o caos cedeu espaço para que surgissem brincadeiras, a fala, a afetividade, a curiosidade.

Em atividades tais como assistir a um filme, os alunos passaram a comentar as cenas, brincar em relação a quais personagens cada um se parecia, ficar tristes, felizes, chorar e até vibrar com a história pedindo para assistir novamente. Pode-se pensar que esse diálogo com o filme e com as histórias criou um espaço para a imaginação e para a fantasia, para que as crianças pudessem se experimentar enquanto sujeitos. A fabulação e o brincar permitem exercitar o vir a ser, transitivar, levantar hipóteses, criar elementos imaginários que vão sustentar uma constituição subjetiva.

Mannoni (em Kupfer, 2005) enfatiza a possibilidade e a importância da presença da Psicanálise não só nos atendimentos ou na escuta das questões institucionais, mas também na montagem, na estrutura e na proposta de uma instituição. A autora propõe o que chama de alternância entre os vários espaços institucionais, referindo-se à família, à escola e a outras 
instituições. Ao fazer a criança ou o adolescente circular alternadamente entre esses diversos espaços, busca-se a possibilidade de surgir, pela ausência ou hiância que se cria entre esses espaços, a dimensão da falta, um registro do que não está mais. Dessa forma, a montagem da instituição pode reproduzir uma cadeia de significantes, e se espera que o sujeito surja no intervalo entre eles.

Conforme refere Ireland (2005), a escola, ou se podemos considerar, as instituições educacionais, são espaços por onde circulam angústias, desejos e falta, expressão e apaziguamento pulsional, processos identificatórios, forças inconscientes e conflitos de toda a ordem. Ao circular pelas instituições, a criança e/ou $o$ adolescente pode estar empreendendo uma busca, aliada à esperança de ser compreendido. De acordo com a autora, trata-se de um espaço privilegiado onde "podem ocorrer avanços no processo de (auto) constituição do sujeito e da constituição de um lugar no mundo onde esse sujeito possa se reconhecer" (p. 58). Dessa forma, a instituição pode se constituir num espaço de continência para seus conflitos.

Guerra (2005), Monteiro e Queiroz (2006) e Soares (2007) referem que, no campo do serviço público, o principal eixo de contribuição da Psicanálise é a questão do sujeito. De acordo com Monteiro e Queiroz (2006), "assegurar a dimensão da clínica na prática institucional é sustentar o lugar social do sujeito a partir de sua diferença, e não do universal dos direitos de cidadão" (p. 113).

Guerra (2005) refere que o ideal de um atendimento que seja destinado "para todos" não pode ser confundido com a ideia de um atendimento que pode ser feito de forma "igual para todos". Nesse sentido, o autor ressalta que a Psicanálise permite sustentar a diferença de "cada um" na escuta à singularidade que o constitui. Passar do singular, do único, do disjunto que é o "cada um", para o coletivo, o "para todos", não implica uma passagem para o universal (p. 150).

Pode-se levantar a hipótese de que sustentar uma escuta psicanalítica singular, dando espaço para o sujeito, é um dos grandes desafios para quem se propõe à escuta clínica nas instituições. Por isso, entende-se que, ao sustentar esse lugar, ocupa-se uma posição de escuta e de ato: escuta-se a instituição a partir do discurso e das práticas dos agentes institucionais, das relações estabelecidas entre os atendentes e destes com os atendidos e da posição que a instituição ocupa no meio em que está inserida; os agentes institucionais, buscando-se o que há de mais singular naquilo que é coletivo e de coletivo no singular; e, por fim, as crianças e adolescentes imersos nessa dinâmica social, institucional e pulsional.

\section{Sobre a transferência: algumas especificidades no contexto institucional}

Considera-se que uma das importantes contribuições da Psicanálise, tanto para o trabalho no setting tradicional - consultório - quanto nas instituições ou onde quer que esteja, aquele(a) que se propõe à escuta clínica, é a ideia de que o trabalho é sempre singular, e só acontece no encontro com o outro (e o Outro). Portanto, não basta transpor teorias e técnicas para a prática, o trabalho acontece na e pela transferência, e a forma como se estabelece dependerá da singularidade de cada sujeito/instituição e da história de cada tratamento.

No campo de trabalho do serviço público, a transferência é um conceito muito importante para a prática. Para Figueiredo (2005), falar em transferência não se refere apenas a essa concepção que remete à resistência e aos sentimentos amorosos ou hostis vividos precocemente pelo sujeito e atualizados no tratamento analítico. Trata-se do conceito em sua acepção simbólica, que remete à demanda ao saber, de suposição de saber. Enquanto no tratamento analítico a suposição de saber passa pelo analista, no trabalho em equipe ela circula entre os pares e dirige-se ao sujeito do inconsciente.

Kupfer (1997) e Figueiredo (2005) utilizam a expressão transferência de trabalho, proposto por Lacan. Trata-se de um instrumento de trabalho entre pares, a condição do estabelecimento de um laço produtivo, que visa o fazer clínico e a produção de saber que lhe é consequente. A transferência de trabalho é vista como possibilidade diante das rivalidades narcísicas provocadas pelas pequenas diferenças entre os iguais e deve ocorrer entre os profissionais da equipe para que as intervenções possam ser coerentes e ter o efeito desejado.

No âmbito da clínica institucional, o conceito de transferência sustenta teórica e tecnicamente a atuação do técnico de referência. De acordo com Zanetti e Kupfer (2006), "o tipo de transferência que se estabelece com este profissional aproxima-se daquele que se instala em um atendimento individual, embora não se trate da neurose de transferência classicamente descrita por Freud" (p. 181). Para as autoras, esses 
são os chamados fenômenos transferenciais, a partir dos quais é possível o manejo da transferência e até mesmo a construção de uma hipótese diagnóstica.

No Lar da Infância, pode-se observar que, ao circular pelos diferentes espaços realizando atividades coordenadas por diferentes profissionais, as crianças e adolescentes têm a possibilidade de se representar de formas diferentes na própria instituição. Um dos discursos cristalizados entre os agentes institucionais era de que, além de serem poucos os alunos que se interessavam em participar das atividades, eram sempre os mesmos. Aos poucos, esse discurso passa a não encontrar sustentação e ser questionado, quando se percebe que os alunos demonstram habilidades e interesses variados, dependendo das atividades e da forma como se estabelece a transferência com os profissionais de referência nessas atividades. Por exemplo, a Hora do Conto é uma das atividades na qual, frequentemente, os alunos não querem apenas ouvir a história, mas contar as suas histórias. Falam sobre suas vivências pessoais, familiares ou da comunidade, sobre questões institucionais, e sobre suas histórias favoritas, tais como as lendas urbanas. Uma das lendas urbanas trazida pelos alunos e trabalhada pela professora foi "A loira do banheiro". Levantou-se a hipótese de que se trata de uma forma simbólica de falar de questões referentes à sexualidade, numa turma com vários alunos marcados pela exposição precoce à sexualidade adulta.

Outro exemplo: uma das atividades propostas pelo Setor de Psicologia na instituição Lar da Infância é o Espaço da Escuta. Trata-se de um espaço destinado para trabalhar as questões emergentes de cada turma. Em uma das turmas, com crianças de sete a oito anos, os alunos têm tendência a serem agressivos verbal e até fisicamente com os colegas novos, chegando ao ponto de alguns desistirem de frequentar a instituição. Ao trabalhar essa questão, um dos desdobramentos possíveis foi a brincadeira de papai e mamãe, quando dois alunos fazem de conta que são os pais e os demais são outros membros da família, tais como: filhos, tios ou empregados. No entanto, essa brincadeira acontecia também em outros setores, tais como o espaço do brinquedo ou no pátio. Quando esse tema veio à tona e a equipe pode discutir e entender que brincar de faz de conta se constituía um movimento saudável da turma, a brincadeira pode ser acolhida pelos profissionais. Dessa forma, pode-se pensar que, de uma forma lúdica, essas crianças construíram uma possibilidade para elaborar a entrada desses novos alunos/irmãos, que, assim como acontece em uma família, mudam todo um contexto familiar e o lugar que cada um ocupa na relação com os pais ou cuidadores.

Nomear uma sala de Espaço de Escuta gerou questionamentos tanto nos alunos quanto na equipe. Foi dito que se trata de um espaço onde a proposta é que os alunos possam falar e ser escutados. A proposta teve ressonâncias na instituição, e até mesmo alguns profissionais de outras áreas puderam se apropriar da ideia, dando espaço para que os alunos por eles atendidos pudessem ser escutados durante a realização de outras atividades, contando sobre o que se passa na escola, no bairro onde moram ou na própria instituição. Cabe salientar que esses profissionais escutam de outra forma, conforme o entendimento de cada um, mas o importante é o espaço que se constrói para a palavra, para as trocas e, pode-se dizer, para os sujeitos.

Baio (citado por Soares, 2007) refere que a "prática entre vários" ${ }^{4}$ atua na relação com o saber e torna-se uma ferramenta importante no tratamento da psicose. Ao realizar o revezamento, os profissionais regulam e limitam os saberes entre cada um e mostram que nenhum deles detém o saber último. Dessa forma, coloca em cena um Outro regulado, barrado, castrado do saber. O autor enfatiza que os vários que podem participar dessa prática não dependem de possuir um saber de especialista, pois o que importa é a presença e o testemunho que ajudam a criança a empreender a construção de seu próprio saber. Zenoni (citado por Abreu, 2008) refere que a instituição tem uma dupla função: a de acolher e a de tratar. O acolhimento é uma demanda do social, acompanhada por situações de passagens ao ato, psicoses, fenômenos clínicos, depauperamento físico, dentre outras. Quanto ao tratamento, a instituição permite uma terceira via: "um lugar onde a clínica se faz operar e onde o sujeito se faz acolher, que permite uma passagem de uma clínica a dois, a uma clínica dita coletiva: uma clínica feita por muitos, uma prática entre vários" (p. 76).

4. A "prática entre vários" ou, em francês, "pratique à plusieurs", foi um termo cunhado por Jaques Alain-Miller para designar a modalidade de atendimento a crianças psicóticas e neuróticas graves, desenvolvida inicialmente em uma instituição Belga fundada por Antonio di Ciaccia, em 1974. Nesta, os profissionais eram considerados acompanhantes, parceiros daquelas crianças, sendo obrigados a despirem-se dos saberes já formulados para reinventar um novo saber, construído pela própria criança (Soares, 2007). 
Por fim, é importante ressaltar que, para Vilhena e Amaral (2002), a intervenção psicanalítica deve perpassar a dinâmica institucional, sendo indispensável o trabalho com todos aqueles que se ocupam das crianças, os agentes institucionais: "O lugar da Psicanálise na instituição não deverá circunscrever-se ao atendimento às crianças, mas ampliar-se para a escuta dos educadores, uma vez que serão os adultos os suportes das angústias vivenciadas pelas crianças" (p. 206).

$\mathrm{Na}$ proposta em questão, o lugar, a partir do qual se propõe um trabalho de escuta das questões institucionais e de acolhida ao discurso dos agentes institucionais, é enquanto "um a mais" numa prática que é feita por muitos, conforme define Monteiro e Queiroz (2006). Portanto, enquanto membro de uma equipe composta por profissionais de diferentes áreas, entende-se que o específico da profissão é localizar e trazer para a cena aquilo que se repete e que faz sintoma ou provoca passagens ao ato, seja em relação à instituição, aos atendentes ou atendidos.

Como refere Lebrun (2009), no trabalho institucional é necessário estar em uma posição justa, o que não é necessariamente estar ao lado da subversão ou da ejeção, o que poderia representar um sintoma perverso ou uma reivindicação histérica. Trata-se de considerar as leis que regem o inconsciente. "Diante do que o sujeito deve se situar não é mais um critério externo pertencente a uma ética do bem, mas referência a uma lei interna, o imperativo da castração" (p. 71). Da mesma forma que, para Figueiredo (1997), o psicanalista não deve ser o inconveniente na instituição, visto como "uma espinha de peixe atravessada na garganta da instituição" (p. 168) ou o que convence (em francês: $\operatorname{con}=$ otário; vainc = que vence $)$ ou, ainda, o que é conveniente, um ser dócil e agradável: "O psicanalista que convém, convive. E o faz através do jogo, nada fácil, da política institucional da qual está livre em seu consultório" (p. 168).

\section{Trabalhando as repetições e construindo espaços para os sujeitos}

Em Psicanálise, é sempre no a posteriori que as questões podem ser significadas ou ressignificadas e elaboradas. Em relação à instituição em questão, é possível levantar a hipótese de que as mudanças ajudaram a romper com um ciclo de violência e de atuações que repercutia discussões em vários âmbitos do serviço público e na sociedade. No entanto, cabe salientar que essas medidas por si não representaram a possibilidade de que, a partir de então, a instituição pudesse cumprir seu papel de forma adequada e satisfatória.

Apesar de ser um serviço público destinado ao atendimento à comunidade, independentemente de classe social, situação econômica e nível de vulnerabilidade, parte das crianças e adolescentes atendidos é proveniente de um meio onde a violência e a criminalidade estão muito presentes, encontrando-se em situação de vulnerabilidade social e psíquica. Essas marcas provocam efeitos na instituição e nos agentes institucionais.

Dessa forma, é possível levantar a hipótese de que a situação de negligência, abandono, violência e a falta de investimento na instituição e, desta, em relação aos seus atendidos, representavam, de alguma forma, repetições de uma cadeia de significantes. Como aparece no discurso de uma das agentes institucionais, ao entrar na instituição, "esse lugar parece que faz parte do bairro São Pedro (nome fictício)", local onde se concentra o maior número de situações de violência e tráfico de drogas da cidade e no qual residem muitos alunos atendidos.

Laznik-Penot (1989) no texto "Seria a criança psicótica “Carta Roubada'?” escreve sobre a repetição dos significantes pelos membros de uma instituição, no cuidado com crianças psicóticas. Trazendo alguns casos clínicos para exemplificar o determinismo da cadeia significante que se repete, a autora observa que, em muitos casos, o esquema repetitivo se reapresenta na instituição com o mesmo texto dramático e os mesmos papéis, podendo esses papéis ser desempenhados por diferentes atores. Conforme as palavras da autora, "a mudança de posição com relação à criança implicando mesmo numa mudança de papel por determinado ator, permanecendo, porém o cenário fixo, assim como os personagens" (p. 51).

De acordo com Laznik-Penot (1989), o que ocorre numa instituição pode ser pensado como expressão do determinismo da cadeia do significante, exercendo-se sobre a intersubjetividade dos protagonistas. Nesse caso, a criança psicótica ocupa o chamado "lugar excêntrico" para os protagonistas de uma equipe de atendimento nas instituições, e talvez também em sua família. Conforme Lacan (1966/1998), é no automatismo de repetição que é preciso situar o sujeito do inconsciente. Dessa forma, a criança funcionaria como a carta roubada, que estando em posse de diferentes atores, exerce certo determinismo, levando-os a representar os mesmos papéis. 
Para tratar dessa questão, alguns fragmentos de dois casos clínicos, lembrando que, para Guerra (2005), a clínica do caso a caso, que considera as especificidades de cada situação, torna-se um instrumento importante para o trabalho em instituições. De acordo com a autora, a construção do caso clínico deve ser feita a partir da junção da singularidade (psicanálise) e da ação coletiva (campo da atenção psicossocial): "Indo além das especialidades, é o Um do caso que nos permite adotar, no campo da saúde mental, uma 'prática feita por muitos" (p. 118).

Rogério (nome fictício) tem 11 anos. Ele mora com uma família adotiva desde bebê, depois que a mãe adotiva se recuperou de um grave acidente e, como não poderia mais conceber filhos, fez a promessa de realizar a adoção de uma criança com necessidades especiais. Da história pregressa sabe-se apenas que a mãe biológica era usuária de drogas e perdeu a guarda dos filhos por agressão e negligência. Apesar de trazer na face traços característicos que remetiam ao pai adotivo, a hipótese da paternidade biológica nunca foi confirmada.

Rogério circulava em quatro diferentes instituições: a família, a escola regular, a escola especial e o Lar da Infância. Tanto a família quanto as demais instituições delegavam a responsabilidade e os cuidados de uma para outra, com enfáticas discussões em relação aos atendimentos e aos períodos em que Rogério deveria frequentar cada uma das instituições. Os pais, por sua vez, repetiam o discurso de que se arrependeram da adoção e já tentaram "devolver" Rogério várias vezes, sem êxito.

Mudam os atores, permanecem os personagens. Nas instituições, a presença de Rogério incomodava alguns e causava comoção em outros, provocando cisões na equipe. Rogério agredia ao mesmo tempo em que era agredido pelas instituições. No Lar da Infância, Rogério apresentava problemas de conduta: agredia crianças menores, roubava, mentia e danificava objetos. O mal-estar culminou no momento em que, ao fazer o que considerou uma brincadeira com uma adolescente, $\mathrm{o}$ ato foi interpretado como agressão e Rogério desligado da instituição. Como refere Lacan (1966/1998), para quem não banca o avestruz, enfiando a cabeça na areia, esses significantes que se repetem não passam despercebidos, mesmo que muitas vezes não se saiba o que fazer com eles.

Outro fragmento de caso clínico: Isaura tem sete anos e mora com a avó materna, mãe adotiva de sua mãe. Traz seu corpo marcas de negligência e abandono, depois de ter convivido com a mãe durante seus primeiros anos, enquanto ela circulava por diferentes pontos da cidade roubando e se prostituindo para conseguir dinheiro e consumir drogas. Antes de ser cuidada pela avó materna e por seu companheiro, Isaura residiu um breve período com a família paterna, porém eles também perderam a guarda por negligência.

Isaura chegou à instituição aos cinco anos: não aceitava ajuda e procurava ficar distante da equipe, batia nos colegas e se irritava com as crianças que choravam. Numa das atividades pegou uma goma de mascar de uma professora, sem autorização. Carinhosamente, a professora acolheu Isaura. Na semana seguinte, ao receber uma goma de mascar dessa mesma professora, Isaura disse: "Você conhece a música: avião sem asa, piu-piu sem frajola, sou eu assim sem você...." Ao falar sobre o ocorrido com colegas da equipe, a professora se emocionou, dizendo que Isaura precisava muito da ajuda da instituição. A intervenção e a comoção da professora provocaram ecos na instituição e, aos poucos, os demais profissionais passaram a reconhecer que Isaura também era capaz de demonstrar doçura e meiguice, com disponibilidade para dar e receber afeto. Nesse mesmo período, a menina passou a pedir colo para o professor de dança e aos poucos pode reconhecer a existência de outros adultos que eram capazes de ocupar um lugar de cuidado, continência e afeto. Isaura parece ter encontrado um espaço na instituição onde lhe é permitido ser criança. Todos os dias, ela questiona quais serão as atividades das quais irá participar e, indo ao encontro de uma das agentes institucionais, se oferece para ser cheirada (quase como um bebê, no terceiro tempo do circuito pulsional) ${ }^{5}$.

Ao contrário do que aconteceu com Rogério, situação em que a instituição não conseguiu romper com o determinismo da cadeia significante e o menino foi desligado, com Isaura parece que a instituição

5. O circuito pulsional refere-se ao árduo trabalho de um sujeito nascer, de fato. No primeiro tempo do circuito pulsional, o bebê vai em busca do objeto da satisfação oral (peito, mamadeira), sendo entendido com um tempo ativo. No segundo tempo, o bebê tem uma experiência alucinatória de satisfação, seja chupando uma chupeta, o próprio dedo, entre outros. Essa experiência está ligada ao autoerotismo. No terceiro tempo, que é tido como de satisfação pulsional, a criança vai se fazer de objeto de um novo sujeito. Ela se assujeita a um outro, se oferece para a mãe e, nesse jogo de aparente passividade, busca fisgar o Outro materno que vai lhe permitir nascer enquanto sujeito (Laznik, 2004). 
consegue, de alguma forma, provocar um movimento, utilizando uma estratégia semelhante ao que Monteiro e Queiroz (2006) chamam de contenção afetiva. Com uma intervenção simples, trivial, a professora faz com que a ideia de uma criança agressiva, forte, independente e distante sofra um esvaziamento de sentido no discurso da equipe, e que Isaura consiga se representar de outras formas entre os cuidadores, estabelecendo relações de afeto, cuidado e construindo espaço para ser uma criança.

Para que a contenção afetiva tenha efeitos, Monteiro e Queiroz (2006) ressaltam que a transferência deve ser manejada a partir dos sinais dados pelo aluno/paciente. Com certa dose de invenção, o profissional pode fazer-se de capitonê e destinatário desses sinais mínimos e, dessa forma, operar na e pela transferência: "É preciso entrar na matriz do discurso pelo sinal e não pelo sentido, o que supõe decidir que existe aí uma entrada possível" (Miller, citado por Monteiro e Queiroz, 2006, p. 116).

Para Laznik-Penot (1989), a instituição deve criar condições para que os mecanismos de repetição possam ser localizados e para que seja possível desvencilhar-se deles. Isso não garante que a repetição não mais aconteça, mas, sim, a possibilidade de que novos significantes possam surgir, buscando-se romper com a rigidez e o determinismo da repetição. Essas condições podem ser dadas a partir do momento em que os membros da equipe podem falar sobre o que acontece nas instituições, nos estudos de caso ou na discussão de casos e, principalmente, com o auxílio da supervisão. Numa analogia ao tempo lógico proposto por Lacan (1966/1998), na instituição, os fatos se dão a ver. No entanto, é preciso um tempo para compreender que implica tirar o significante de seu monossentido, devolvendo-lhe a polissemia. Por fim, o momento de concluir, que marca a possibilidade de que algo novo possa surgir.

Por isso, pode-se pensar que, no trabalho institucional, não se trata de almejar a construção de uma instituição ideal, o que nos remeteria sempre ao imaginário. Trata-se, no entanto, de possibilitar amarrações simbólicas para que a instituição possa cumprir seu papel. E, talvez, uma instituição possível, na atualidade, seja aquela que permita aos que dela fazem parte (sejam eles os atendidos ou os atendentes) condições para que os sujeitos possam se representar de outras formas no social. Para essas crianças e adolescentes que trazem em seu corpo e em seu psiquismo as marcas da violência e da exclusão, que ao conviver na instituição possam inscrever outras marcas, podendo se reconhecer enquanto sujeitos, a partir de outros significantes.

\section{Considerações finais}

Na prática psicanalítica, é a partir de estudos singulares que se pode compreender e ampliar as questões da clínica, seja realizada no settingdo consultório tradicional ou em uma instituição. Em relação a este trabalho, acredita-se que uma das contribuições é a ideia de que não devemos recuar frente ao caos com o qual muitas vezes nos deparamos nas instituições. Os espaços para o trabalho nem sempre estão prontos e quem demanda a intervenção geralmente não tem clareza daquilo que está pedindo, sendo necessário escutar os discursos que circulam nas instituições e a partir disso construir um espaço para que esse trabalho aconteça. Nesse sentido, ao propor a ideia da construção de espaços, como sendo uma das possibilidades de trabalho a partir da escuta clínica psicanalítica em instituições, trata-se da construção de espaços físicos, reconhecendo a importância destes para a instituição em questão, mas principalmente da construção de espaços psíquicos para os sujeitos.

Na instituição pública, frequentemente nos deparamos com muitas situações distantes do que a nossa capacidade de compreensão alcança. Situações-limite, de violência, abandono, negligência e exclusão, as quais crianças e adolescentes precisam enfrentar no seu cotidiano. E por isso também a dificuldade do processo de escuta e acolhida desses sujeitos, pelos profissionais que ali trabalham, levando a instituição a repetir essas situações. Fazendo uma analogia ao texto de Laznik-Penot (1989), usado como referência neste trabalho, se caímos em posse das muitas cartas que circulam num contexto institucional, não somos nós que as possuímos, mas são esses significantes que nos possuem.

Por isso, levanta-se a importância dos espaços de supervisão e de análise pessoal, pois, se no tratamento tradicional existe um setting que protege o profissional ao mesmo tempo em que protege o paciente, no trabalho institucional, muitas vezes, o trabalho se constrói pela posição que se ocupa na instituição, ou seja, pelo lugar transferencial. Nesse sentido, um aspecto a ser analisado, nesta produção, é o lugar de onde se fala: de dentro da instituição. Sabe-se de todas as implicações deste lugar, já que, 
mesmo buscando algum distanciamento pela via da supervisão, da análise pessoal e até mesmo desta produção, não há como isentar a escrita e as escolhas que se faz, de estarem atravessadas tanto pelas questões institucionais quanto pelas questões de ordem pessoal/narcísica.

Por fim, apesar da resistência e do caos com os quais nos deparamos na prática, entende-se que o trabalho deve ser guiado pelo objetivo de que as crianças e adolescentes que fazem parte de uma insti-

\section{Referências}

Abreu, D. N. (2008). A prática entre vários: a psicanálise na instituição de saúde mental. Estudos e Pesquisas em Psicologia, 8(1), 74-82. Recuperado de http:// www.e-publicacoes.uerj.br/index.php/revispsi/article/view/ 10849

Brasil (1996). Lei no 9.394, de 20 de dezembro de 1996. Estabelece as diretrizes e bases da educação nacional. Diário Oficial da União. $23 \mathrm{dez}$.

Coutinho, L. G., \& Rocha, A. P. R. (2007). Grupos de reflexão com adolescentes: elementos para uma escuta psicanalítica na escola, Psicologia Clínica, 2(19),71-85. doi:10.1590/S0103-56652007000200006

Figueiredo, A. C. (1997). Vastas confusões e atendimentos imperfeitos: a clínica psicanalítica no ambulatório público. Rio de Janeiro, RJ: Relume-Dumará.

Figueiredo, A. C. (2005). Uma proposta da psicanálise para o trabalho em equipe na atenção psicossocial. Mental, 3(5), 44-55. Recuperado de http://pepsic.bvsalud.org/scielo.php?pi$\mathrm{d}=$ S1679-44272005000200004\&script=sci_arttext

Freud, S. (1976). Linhas de progresso na terapia psicanalítica. In Edição standard brasileira das obras completas de Sigmund Freud (Vol. 17, pp. 199-211). Rio de Janeiro, RJ: Imago. (Trabalho original publicado em 1919[1918]).

Freud, S. (1980). Psicologia das massas e análise do eu (1921). In Edição standard brasileira das obras psicológicas completas de Sigmund Freud (Vol. 18). Rio de Janeiro, RJ: Imago. (Trabalho original publicado em 1921).

Guerra, A. M. C. (2005). A psicanálise no campo da saúde mental infanto-juvenil. Psyché, 15(4), 139-154. Recuperado de http://www.pucminas.br/documentos/psicanalise_campo_saude_mental_infanto_juvenil.pdf tuição possam ser reconhecidos enquanto sujeitos, na sua singularidade, e que dessa forma, possam encontrar um espaço de simbolização e de reconhecimento da capacidade interna que possuem. Dentro dos limites e das possibilidades de cada caso, levanta-se a hipótese de que a escuta clínica psicanalítica possibilita uma importante contribuição para a busca de melhores condições, para que as instituições sejam um ambiente mais saudável para o desenvolvimento e a constituição de sujeitos.

Ireland, V. E. (2005). A escola e a criança desenquadrada. In I. B. Vita, \& F. C. B. Andrade (2005), (Des) fiando a trama: a psicanálise nas teias da educação (pp. 53-75). São Paulo, SP: Casa do Psicólogo.

Kaufmann, P. (1996). Dicionário de psicanálise. Rio de Janeiro, RJ: Jorge Zahar.

Kupfer, M. C. M. (1997). O que toca à/a psicologia escolar. In A. M. Machado, \& M. P. R. Souza (Orgs.), Psicologia escolar: em busca de novos rumos (pp. 51-61). 3a ed. São Paulo, SP: Casa do Psicólogo.

Kupfer, M. C. M. (2005). Psicanálise e instituições. In I. B. Vita, \& F. C. B. Andrade (2005), (Des)fiando a trama: a psicanálise nas teias da educação (pp. 27-35). São Paulo, SP: Casa do Psicólogo.

Lacan, J. (1998). Escritos (V. Ribeiro, Trad.). Rio de Janeiro, RJ: Jorge Zahar. (Trabalho original publicado em 1966).

Lacan, J. (2003). Outros escritos (V. Ribeiro, Trad.). Rio de Janeiro, RJ: Jorge Zahar. (Trabalho original publicado em 2001).

Laplanche, J., \& Pontalis (2001). Vocabulário de psicanálise. 4a ed. São Paulo, SP: Martins Fontes.

Laznik, M.-C. (2004). A voz da sereia. O autismo e os impasses na constituição do sujeito. Salvador, BA: Àgalma.

Laznik-Penot, M-C. (1989). Seria a criança psicótica "carta roubada"? In A. M. Souza (Org.), Psicanálise de crianças (pp. 47-66). Porto Alegre, RS: Artes Médicas.

Lebrun, J. (2009). Clínica da instituição: o que a Psicanálise contribuiu para a vida coletiva. Porto Alegre, RS: CMC Editora.

Monteiro, C. P., \& Queiroz, E. F. (2006). A clínica psicanalítica das psicoses em instituições de saúde mental, Psicologia Clínica, 18(1), 109-121. doi:10.1590/S0103-56652006000100009

Moretto, M. L. T. (2001). O que pode um analista no hospital? São Paulo, SP: Casa do Psicólogo. 
Rosa, M. D. (2004). A psicanálise e as instituições: um enlace ético-político. In Proceedings of the 5. Colóquio do LEPSI IP/FE-USP, 2004. São Paulo. Recuperado de http://www.proceedings.scielo.br/scielo.php?pi$\mathrm{d}=\mathrm{MSC} 0000000032004000100045 \&$ script=sci_arttext

Soares, J. M. (2007). Possibilidades e limites do tratamento psicanalítico da psicose infantil em instituições de saúde mental (Dissertação de mestrado). São Paulo, SP: Instituto de Psicologia da Universidade de São Paulo.

Vilhena, J., \& Amaral, M. E. C. (2001). Em busca de uma certa singularidade. Reflexões acerca da Psicanálise infantil em uma instituição, Psyché, 6(9), 197-211. Recuperado de http://www.redalyc. org/pdf/307/30700915.pdf

Zanetti, S. A. S., \& Kupfer, M. C. M. (2006). O relato de casos clínicos em Psicanálise: um estudo comparativo. Estilos da clínica, 11(21), 170-185. doi:10.11606/issn.1981-1624.v1li21p170-185

\section{Elenice Cazanatto}

Psicóloga na Prefeitura Municipal de Farroupilha. Especialista em Intervenção Psicanalítica na Clínica com Crianças e Adolescentes pela Universidade Federal do Rio Grande do Sul, Porto Alegre - RS. Brasil. E-mail: nicecazanatto@yahoo.com.br

\section{Margareth Kuhn Martta}

Doutora em Educação, Analista Membro da Escola de Estudos Psicanalíticos.

E-mail:zmmartta@uol.com.br

\section{Claudia Alquati Bisol}

Doutora em Psicologia, Professora do Curso de Psicologia e do Pós-Graduação em Educação da Universidade de Caxias do Sul, Caxias do Sul - RS. Brasil. Membro da Escola de Estudos Psicanalíticos. E-mail: cabisol@ucs.br

Endereço para envio de correspondência: Rua Angelina Michelon, n 158, sala 51. Bairro Lourdes, Caxias do Sul/RS.

Recebido: 26/05/2014

Reformulação: 18/05/2015

Aprovado: 03/04/2016

Received:05/26/2014

Reformulated: 05/18/2015

Approved: 04/03/2016

Recibido:26/05/2014

Reformulado: 18/05/2015

Aceptado: 03/04/2016

Como citar: Cazanatto, E., Martta, M. K., \& Bisol, C. A. A escuta clínica psicanalítica em uma instituição pública: construindo espaços. Psicologia: Ciência e Profissão, 36(2), 486-496. doi:10.1590/1982-3703000742014

How to cite: Cazanatto, E., Martta, M. K., \& Bisol, C. A. Listening to Psychoanalytic Clinic at a Public Institution: Building Spaces. Psicologia: Ciência e Profissão, 36(2), 486-496. doi:10.1590/1982-3703000742014

Cómo citar: Cazanatto, E., Martta, M. K., \& Bisol, C. A. Escuchando Clínica Psicoanalítica en una institución pública: Construyendo espacios. Psicologia: Ciência e Profissão, 36(2), 486-496. doi:10.1590/1982-3703000742014 